\title{
The Concept of Lava Flow Controlled Use as a Source of Energy and Materials
}

\author{
VladimirBodyakin and Anuar Kulmagambetov
}

Company Laitingen Financial Inc, Moscow 127410, Russia

\begin{abstract}
Our civilization is facing an urgent need to include innovative, large-scale sources of energy and raw materials into its technological cycles. One potential source is magma, which now still inspires awe with its unpredictable power of volcanic eruptions. We propose a method of remote control of lava flow which is based on a special design of a pipe which is lowered into the crater of a volcano. The magma is raised with the help of a well-known method for raising liquids, the airlift. This article includes a detailed description of the structure of the disperser that we shall use to introduce gas into the magma, explains the possible ways to manage the flow of magma, and describes the results that can be achieved. There is potential for the establishment of a whole new industry that will produce cheap electricity, hydrogen, rare metals, fertilizers and innovative construction materials.
\end{abstract}

Key words: Alternative energy, magma, volcano, airlift, lava, hydrogen.

\section{Introduction}

Volcanoes are not only a powerful, fire-breathing source of constant danger, but also the "ancestors" of many deposits of minerals and metals on our planet, and the potential source of huge amounts of high-quality thermal energy. However, these gigawatts of uncontrollable energy and millions of tons of valuable raw lava are still beyond the reach of human industrial activity. There are many volcanoes scattered around the world, with about 800 of them active. There are volcanoes with open craters and accessible magma lakes (the mirror of a magma lake is located at a depth of 100-150 meters or less from the surface) $[1,2]$. But how do we get through these meters and how do we "scoop" up the red-hot magma, and is there really any chance of using this uncontrollable source of raw materials and energy?

There is no doubt that during a volcanic eruption people are forced to flee from the surrounding area to protect themselves, so any exploitation of volcanic resources is out of the question at the time of this

Corresponding author: Anuar Kulmagambetov, Ph.D., research fields: engineer, mathematics, information systems. devastating and unpredictable phenomenon. We suggest using the raw materials and energy resources of a volcano by controlling it remotely during its lengthy periods of relative calm between eruptions.

The current decade of the 21 st century is characterized by rapidly developing modern technologies and innovations. Technological advances in the sphere of materials make it possible to deal with new challenges, more complex and unexpected, and controlling lava flow is a good example.

What could this process look like? An incoming operator presses a button on an instrument panel, and a 30-50 meter-high magma column rises from the lava lake. Then, having crossed the protective barrier, a flow of magma goes in a powerful stream through a magma duct with a diameter of 3-7 meters and passes through all the stations of the automated production chain, where fumarole gases are taken from it for the needs of the chemical industry; metals and hydrogen are obtained by electrolysis; high-quality thermal energy is used for generating electricity; materials for construction and road castings are obtained; thermal energy is received, mineral fertilizers for agriculture and mariculture. This would mean an extensive use of the internal resources of our planet. A method to 
control lava is outlined below (the application for invention was filed in July 2013).

\section{Method}

2.1 Method for Raising Magma to the Surface and the Facilities used in the Process

The invention is intended for the mining industry, where it can be used for the extraction of lava mass from magma lakes located in craters of active volcanoes or in the cavities of dormant volcanoes or near them, both those with magma easily accessible from the surface and located in their depths. The method of raising magma is based on a well-known principle of raising liquids with airlift installations [3, 4], which include a pipe to raise the liquid and an air pipe, both pipes connected at the bottom with an air duct and with an air separator at the top. It can be used to raise almost any liquid, with a wide range of properties. After the mixture of fluid and air is raised to the surface with this process, the substances are naturally separated due to pressure equalization, and all the air (gas mixture) is emitted into the atmosphere.

The purpose of the proposed facility is to provide a managed and secure lifting of volcanic lava from magma lakes [1], as well as from volcanic cavities, and its transportation to a site where it undergoes complex processing. This is achieved by supplying gas through a disperser lowered into the magma, which results in foaming the magma and lowering its specific weight in a large part of the pipe, and, according to the law of communicating vessels, the level of foamed magma rises. The design of the device that can be used for this purpose is presented below. Fig. 1 shows the general view of the structure, while Fig. 2 shows a more detailed view of the device proposed for raising magma.

Support towers 2 are installed on the slope of a volcano 1 , and the base platform 5 is attached to the towers with cables 3 . Through platform 5 , pipe 6 with the disperser 9 is immersed into the magma. Pipe 8, which supplies gas into the disperser, runs in parallel with tube 6.

In operating mode, the system works as follows. Gas is fed through pipe 8 into disperser 9 , which saturates the magma with gas throughout the volume of the disperser. The size of the disperser depends on the physico-chemical properties of the magma. As the specific weight of the magma is reduced, it rises up through the pipe and flows 20 into cavity 14 and then flows downward through pipe 16 until it reaches the



Fig. 1 General view of the facility. 


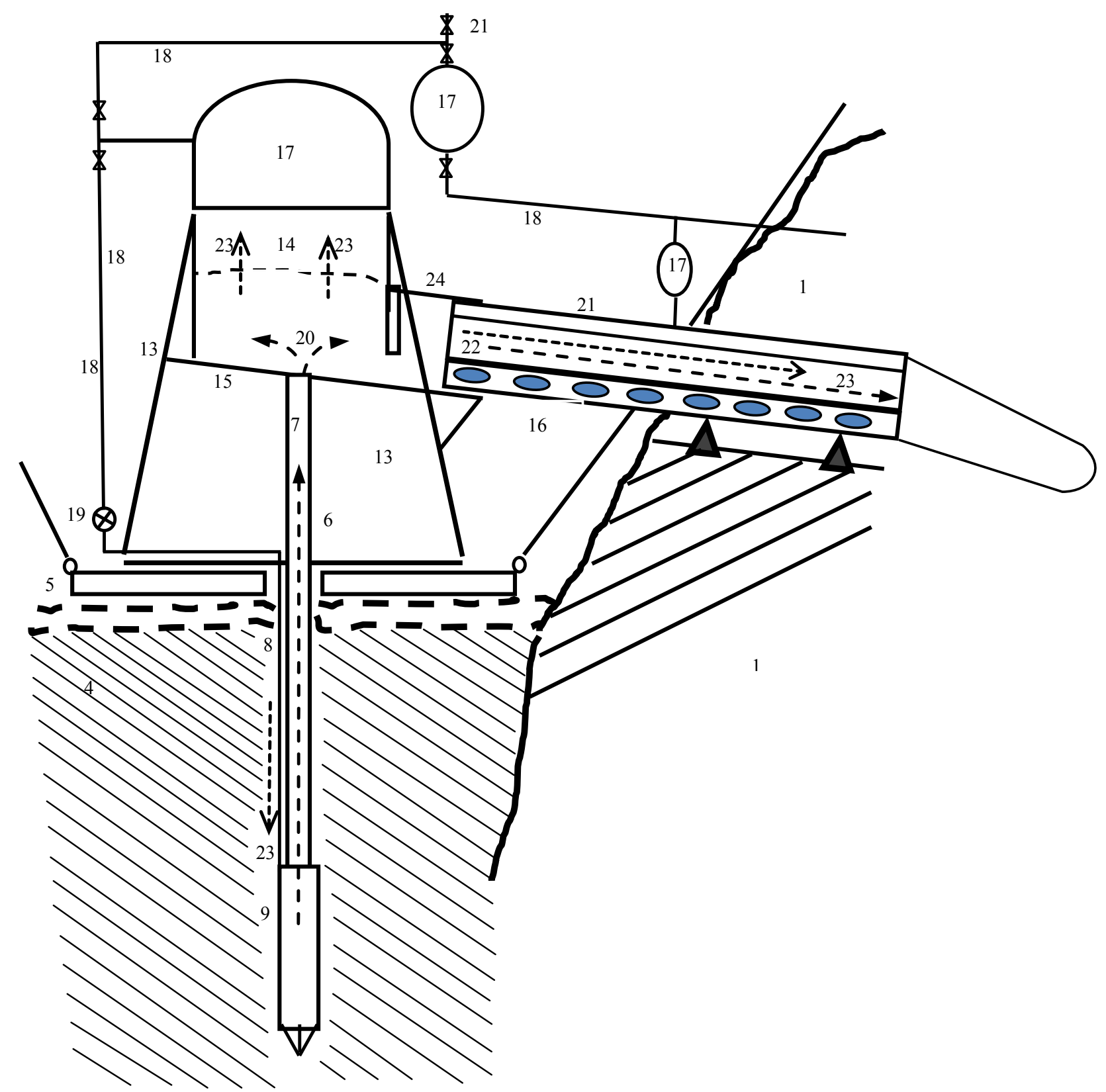

Fig. 2 Scheme of magma lifting facility.

1 - the slope of a volcano, 2 - support tower, 3-cable fixing the platform 5, 4-magma, 6 - main pipe for raising the magma, 7-the inner chamber of the pipe 6,8-gas supply pipe, 9-disperser, 13-outer superstructure, 14-inner cavity of the gas collector, 15-separating platform, 16 - pipe for magma withdrawal, 17-fumarole gas hood, 18 - gas supply pipes, 19-gas supply valve, 20 - magma outflow, 21 - the top part of the gas collection pipe, 22-magma flow, 23 - fumarolic gases flow; 24-magma collector, 25-manufacturing facility for the production of blocks of magma.

manufacturing facility 25 where blocks of magma are cast. Throughout its length, pipe 16 is heated with gas which is burnt in a special cavity under the pipe to ensure a steady flow of magma 22. Fumarolic gases released from the magma are collected in cavities 14, 17 in the upper part of pipe 16 (shown by Arrow 23).
The collected gas is injected into the disperser through pipes 18 or may be supplied for further processing to 21 , for the collection of rare earth metals.

The power of the outgoing magma flow is controlled by changing the pressure of the gas supplied to the disperser. 


\subsection{Volumetric Disperser}

This device is used to mix gas and magma. The size of the disperser may range from $10 \%$ to $75 \%$ of the total length of the pipe used to raise the magma. The scheme of the proposed disperser is presented in Figs. 3a and 3b.

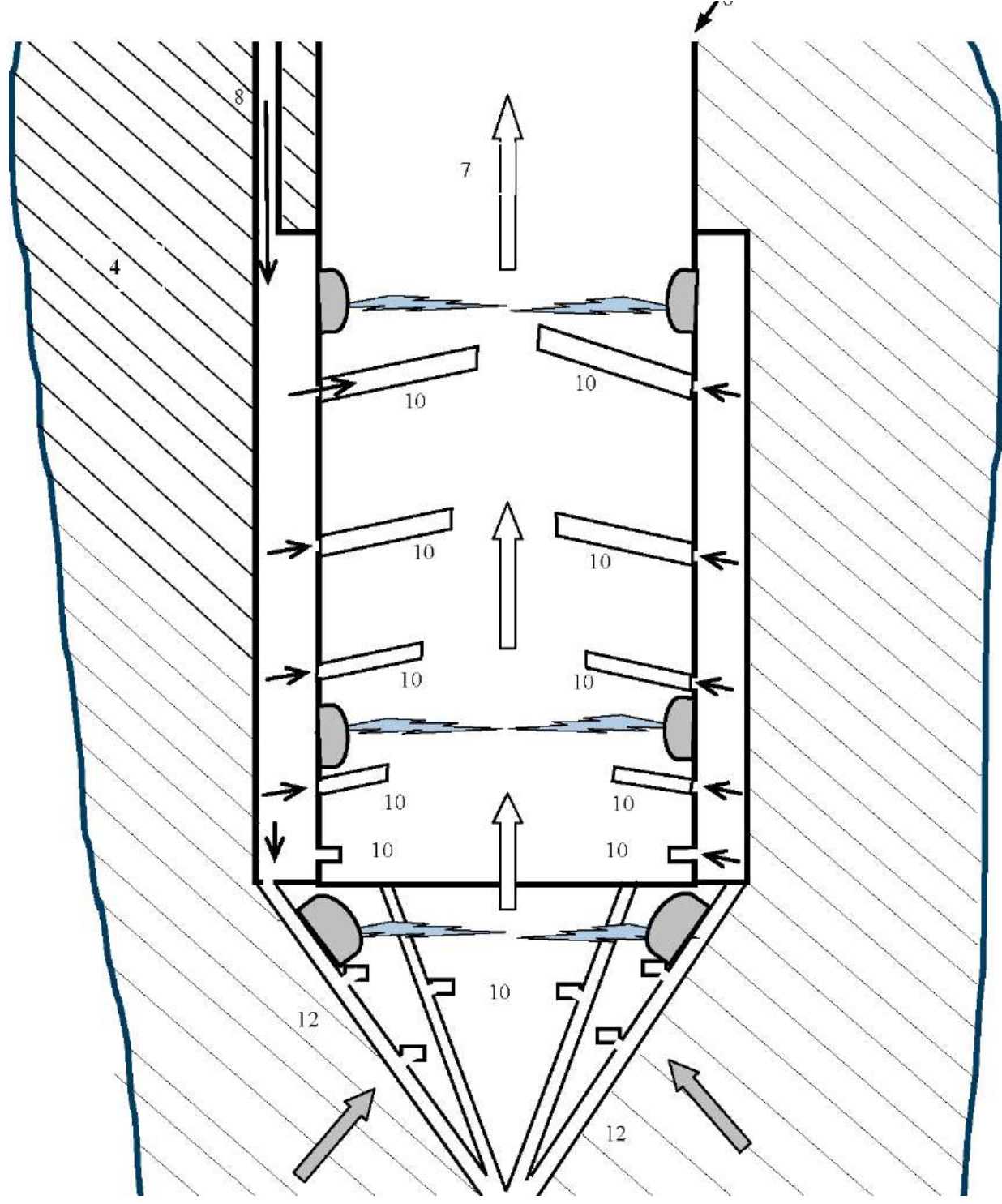

Fig. 3a Volumetric disperser.

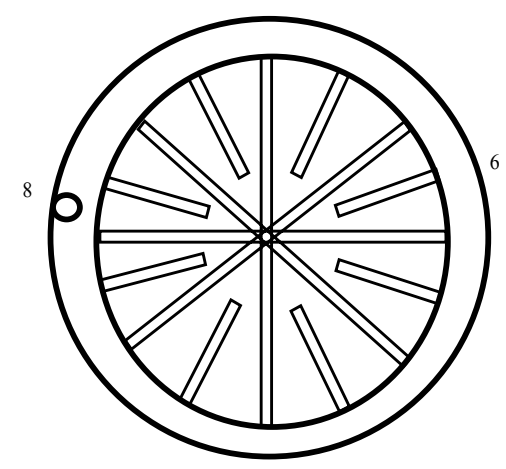

Fig. 3b Disperser: view from the top. 
The disperser is a metal housing that envelops the riser around its perimeter. Between the casing and the pipe there is space into which gas is pumped through pipe 8 of the pipeline. Through special holes, gas flows into tube branches 10, which are attached to the wall of the pipe and directed inside the pipe. Each pipe branch has nozzle holes, through which the gas flows into the magma. Branch pipes of varying length are attached around the perimeter of the pipe, and they can also be directed upwards, along the magma flow. This is done in order to prevent moving magma clots from damaging the pipes. At the bottom, the disperser has a tapered unit, which is also made of pipe branches 12 . The cone is required to reject solid chunks of magma 11 in order to prevent the clogging of the disperser.

Electrical arresters are located along the perimeter of the disperser in order to create discharge and bring about pulse pressure increase in the magma, which "shakes" the magma and crushes its clots and congestions. During its movement, the electrical resistance properties of magma are measured, and when resistance is increased, electrical discharges are produced.

\subsection{The Launch of the Device that Raises Magma to the} Surface

The system has two modes of operation: quick-start mode and process mode. Figs. $4 \mathrm{a}$ and $4 \mathrm{~b}$ show two positions of the system: quick-start mode and process mode.

In Figs. $4 \mathrm{a}$ and $4 \mathrm{~b}$, distinct zones of the lowered pipe are marked (in this case 4). These zones are associated with different pressure levels of the gas fed into the pipe as the lower the magma the higher is the required pressure. In addition, a gas is supplied to the pipe, which in contact with hot magma releases the heat necessary for additional heating of the magma to avoid cooling effect that occurs both with the gas outlet and with the rise of dissolved magma bubbles. The energy released when the gas contacts the magma must be higher than the energy of the compressor used to supply the gas. High pressure in the gas pipe is reduced by a special reducer.

In quick-start mode, the outlet of the riser pipe is lowered to the level of the mirror of the magma lake in order to reduce resistance, as the height of the mass being raised is zero. The Volumetric disperser 9 is

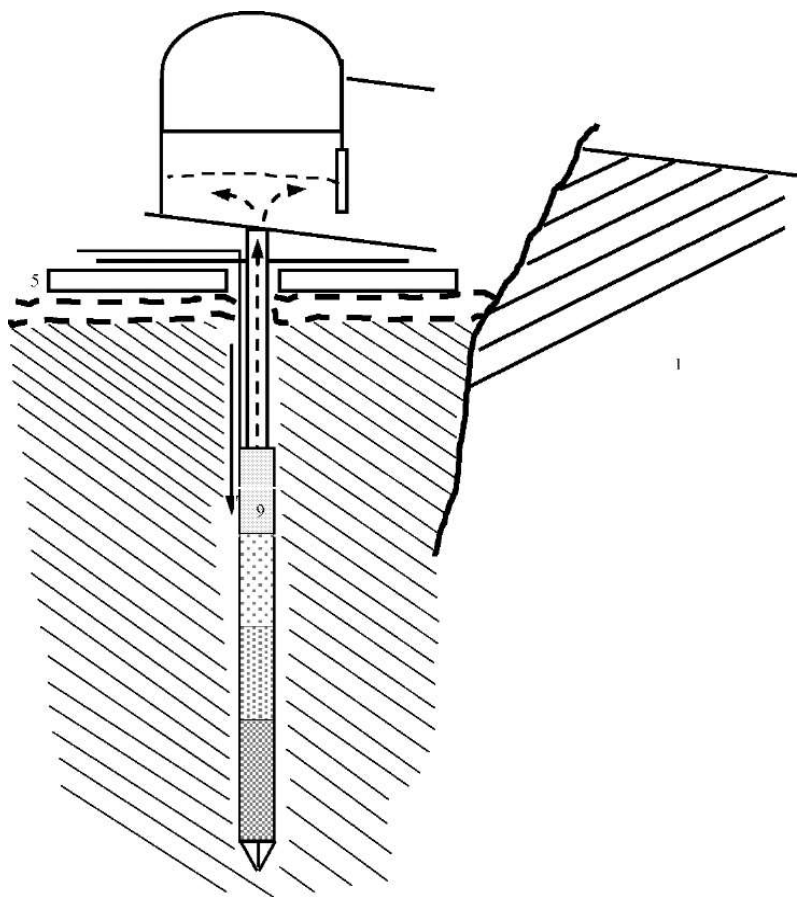

Fig. 4a Quick-start mode.

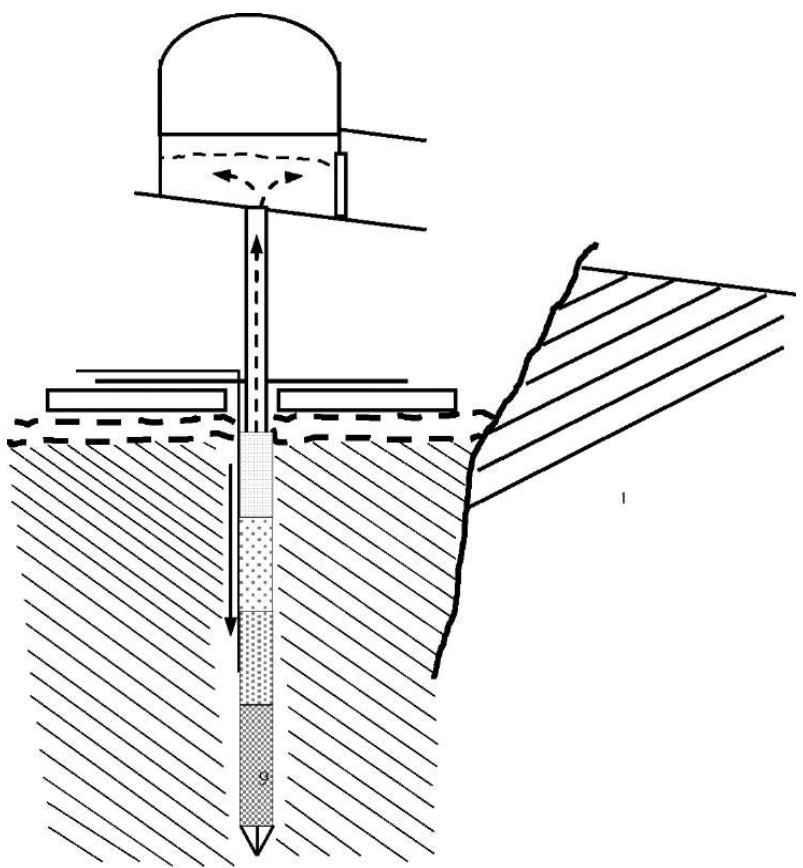

Fig. 4b Process mode. 
started by gas supply. As a result, the whole mass of the original volcanic magma in the riser will turn into gasified magma, forming a stable flow of foamed magma directly into the magma lake. After this, the riser pipe of the airlift is raised slightly above the level of the free flow of lava mass from the riser pipe, technological coupling with the lava collector is effected, and then the system is lowered to the required level which provides for the capacity of the output lava flow required for the needs of production, and the whole process of freely flowing lava is then conducted in the process mode.

A quick start of the airlift can also be effected using a disperser accelerator which is introduced into the riser from above at the initial stage of the process, like graphite rods in nuclear power plants, and gas is fed through vertical branch pipes. Nozzles are also used to introduce gas into magma, with the use of the electro-dischargers.

Once the launch mode has been reached in the riser pipe, the riser pipe is to be connected with the rest of the system and for this purpose it is first raised above the level of the free outflow of foamed magma and then connected with the whole process system and lowered to the level of free process flow of foamed magma, and the whole system starts its work in operating mode.

The process mode requires submerging the pipe to a depth up to 200 meters below the magma mirror lake, and the upper part of the riser pipe column above the magma lake (about 20-70 meters) is covered with a hermetic thermal jacket 13 .

\subsubsection{Theoretical Basis}

It is impossible to raise lava for industrial purposes with any mechanical devices like pumps or scoops, etc., due to the fact that magma cools and turns into a solid state, adhering to all moving mechanical parts of the lifting device and stopping its operation. In practice, it is only possible to manage an ongoing magma flow without mechanical lifting and moving machinery. An airlift is a device which is appropriate for this purpose. It has proven itself in the lifting of liquids, both aggressive liquids and regular water in garden settings. This method, although it is not very efficient, is the only technology available for raising a hot magma flow.

Let us consider the well-known action of forces during the rise of magma in a pipe. Let us record some initial conditions: magma is located in the crater of a volcano (see Fig. 5), the density of magma $\rho_{m}$ and magma viscosity $\eta_{0}$, the pipe with a disperser is lowered into the magma to the depth $\mathrm{h}$.

In an idle state, before gas is supplied into the disperser (gas pressure in the disperser $D_{d}=0$ ), the density of the magma in the riser $\rho_{t}$ is equal to the density of the magma outside it, $\rho_{m}$, i.e.:

$$
\rho_{\mathrm{m}}=\rho_{\mathrm{t}}
$$

Accordingly, the height of the magma column in pipe $\mathrm{H}$ is equal to the depth of the immersion tube $\mathrm{h}$, i.e.,

$$
\mathrm{H}=\mathrm{h}
$$

in accordance with the law of communicating vessels:

$$
\mathrm{h} \times \rho_{\mathrm{m}}=\mathrm{H} \times \rho_{\mathrm{t}}+\mathrm{c}\left(\eta_{0}, \mathrm{~T}\right)
$$

Here $c\left(\eta_{0}, T\right)=$ const. is a correction factor that takes into account the viscosity $\eta_{0}$, the temperature $T$ of the magma, and the resistance of the pipe wall.

During operation of the system, gas is supplied into the disperser at high pressure $D_{1}$, i.e.:

$$
\mathrm{D}_{1}>\mathrm{h} \cdot \rho_{\mathrm{m}}
$$

In this case, the gas entering the disperser reduces the density of the magma in the riser to the level of $\rho_{\mathrm{t} 1}$. Then, based on the law of equilibrium of liquid in communicating vessels:

$$
h \cdot \rho_{m}=H_{1} \cdot \rho_{t 1}+c\left(\eta_{0}, T\right)
$$

We find that the height of the foamed magma in the riser pipe can reach a height of:

$$
H_{1}=\frac{\left(h \cdot \rho-c\left(\eta_{0}, T\right)\right)}{\rho_{t 1}}
$$

Since $\rho_{\mathrm{t} 1}<\rho_{\mathrm{m}}$, then $\mathrm{H}_{1}>\mathrm{H}$, i.e., the magma in the pipe rises and $\mathrm{H}_{1}$ has to exceed the height $\mathrm{H}_{2}$ of magma overflow into the duct (Fig. 5). 


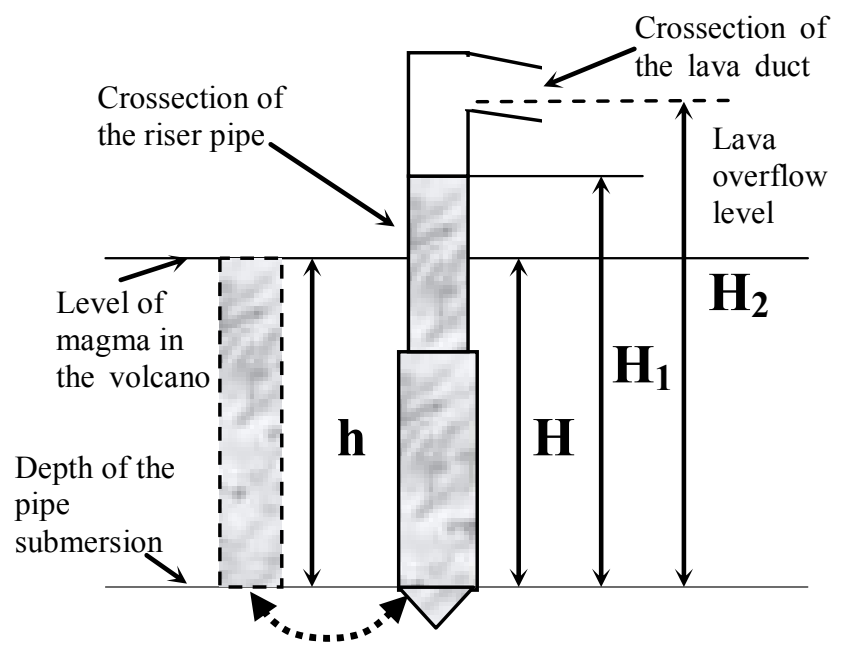

Fig. 5 Scheme of magma lifting pipe submergence.

It is known that, according to Henry's law, the equilibrium concentration of dissolved water in magma is directly proportional to the pressure, and the dependence between the viscosity of the magma and its temperature is described by the Arrhenius dependence [5], i.e., viscosity decreases with increased temperature.

$$
\eta=\eta_{0} \exp \left(E_{\eta} /\left(k_{B} T\right)\right)
$$

where $E_{\eta}=E_{\eta}{ }^{0}\left(1-k_{\eta} C\right)$ is the energy of viscous flow activation; $E_{\eta}{ }^{0}$ is activation energy for the "dry" melt; $k_{\eta}$ is the empirical coefficient; $\eta_{0}$ is the pre-exponential factor; $\mathrm{k}_{\mathrm{B}}$ is the Boltzmann constant.

Thus, the level of magma rising in a pipe depends on the density of the magma in this pipe or the degree of magma gasification [6] at fixed viscosity $\eta_{0}$. It is known that the lower the viscosity of the magma, the easier it is to aerate, and the more aerated it becomes, the lower its viscosity is and the higher it can be raised up the pipe [7].

\subsubsection{Technological Features}

The existence of well-known technological developments of production of reinforced ceramic pipes with a melting point above $1,600{ }^{\circ} \mathrm{C}$ with "water-repellent" cover or air cushion insulation (means small holes in the pipe through which the gas flows and moves away the magma), will be the basis for our production complex, since the temperature of magma ranges from 800 to $1,200{ }^{\circ} \mathrm{C}$.
When lifting the speed of magma flow increases towards the center of the pipe remaining zero at the walls of the pipe due to friction and "cohesion", and "wetting" effects. Therefore abrasive action of magma flow on the pipe wall is controlled and lies within the technologically acceptable bounds. By changing the pressure of supplied gas we control the speed of magma flow, and by changing gas composition we can increase its temperature and viscosity.

As volcano surface consists of solidified lava that has a porous structure and limited overall strength, all facilities which are installed on the volcano slope exert pressure sufficient for them to be stable. For this demand we use the platforms which distribute the load on the large area having all elements of the installation under strict structural coherence and control.

Geological exploration equipment allows detecting presence of voids on the volcano slope, to analyze their conditions and to measure hardness characteristics. This will allow the construction to be well-positioned and to have optimal load distribution. Practice shows that the exerted pressure of the man's foot (average pressure of man's foot is 3 tons $/ \mathrm{m}^{2}$ ) is sufficient for geological exploration and to commence design.

Directional drilling of volcano slope to make a well of 200-400-meter length is not technically a difficult 
task. The slope can be easily drilled (cut), and a relatively small length of the well is required.

\subsubsection{The Control Loop}

As a result, we are able to build a control loop for remote control of the magma flow with feedback (Fig. 6).

Here, the controlling impact (input parameters) includes:

- the pressure of the gas supplied to the disperser,

- chemical composition of the feed gas,

- the degree of magma heating in the magma duct,

- increasing/decreasing the workload of the vacuum pump for output fumarolic gases and control over the level of vacuum.

The managed indicators (output parameters) include:

- the speed of the magma rise,

- the chemical composition of the fumarolic gases,

- the chemical composition of the magma,

- the pressure in the magma duct,

- the speed of magma cooling,

- the temperature and pressure of the superheated water vapor supplied to generate electricity,

- quality of materials produced from magma.

By conducting observation and analysis of the output indicators, the system enables the operator to achieve the specified target parameters by changing the input parameters, i.e., to control the process which is based on magma processing for the purpose of energy generation and manufacture of various products. In metal manufacture, ore is heated to a temperature matching that of magma, which allows a change in the speed and direction of chemical reactions and creates a melt with the desired properties. In our case, the melt already has a very high temperature, and we only need to find out what we can get from it. And this, in turn, will lead to an improvement of the fumarolic gas enrichment technology and the technologies used for manufacturing building materials and other products from magma.

\section{Results and Preliminary Estimates}

Schematic result for all stages is presented in the Fig. 7:

Starting from the third module and further on the production unit may operate as a complete commercially efficient project. Additional modules 8 and 9 of hydrogen production and liquefaction can be built on the remote island. There can be several production lines like this one on one magma heart. The generated electricity surplus by means of electrolysis of water can be converted to hydrogen. The latter can be supplied in large volumes to the market.

The capacity of the magma flow being raised is proportional to the cross section $\left(\mathrm{S}_{1}\right)$ of the riser pipe and the height difference, $\mathrm{H}_{1}-\mathrm{H}_{2}$, (Fig. 5) i.e., pressure on the outcoming magma flow and viscosity $\eta_{1}$ is inversely proportional to magma gasification $\left(\eta_{1}<\eta_{0}\right)$. Theoretically accurate calculation of the magma flow power in the airlift is impossible because the physico-chemical properties of the magma have not

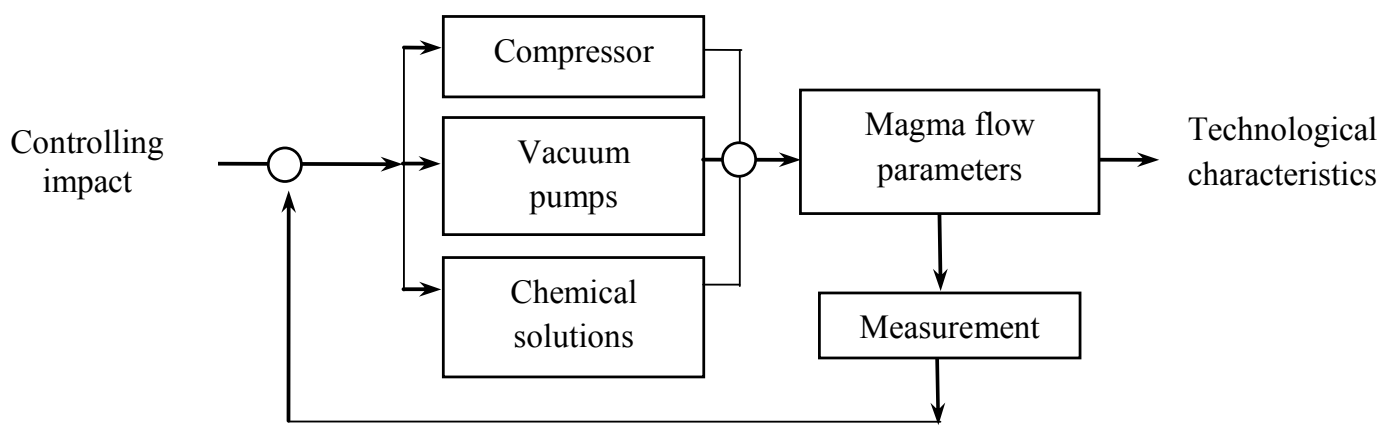

Fig. 6 The scheme of magma flow parameters control. 


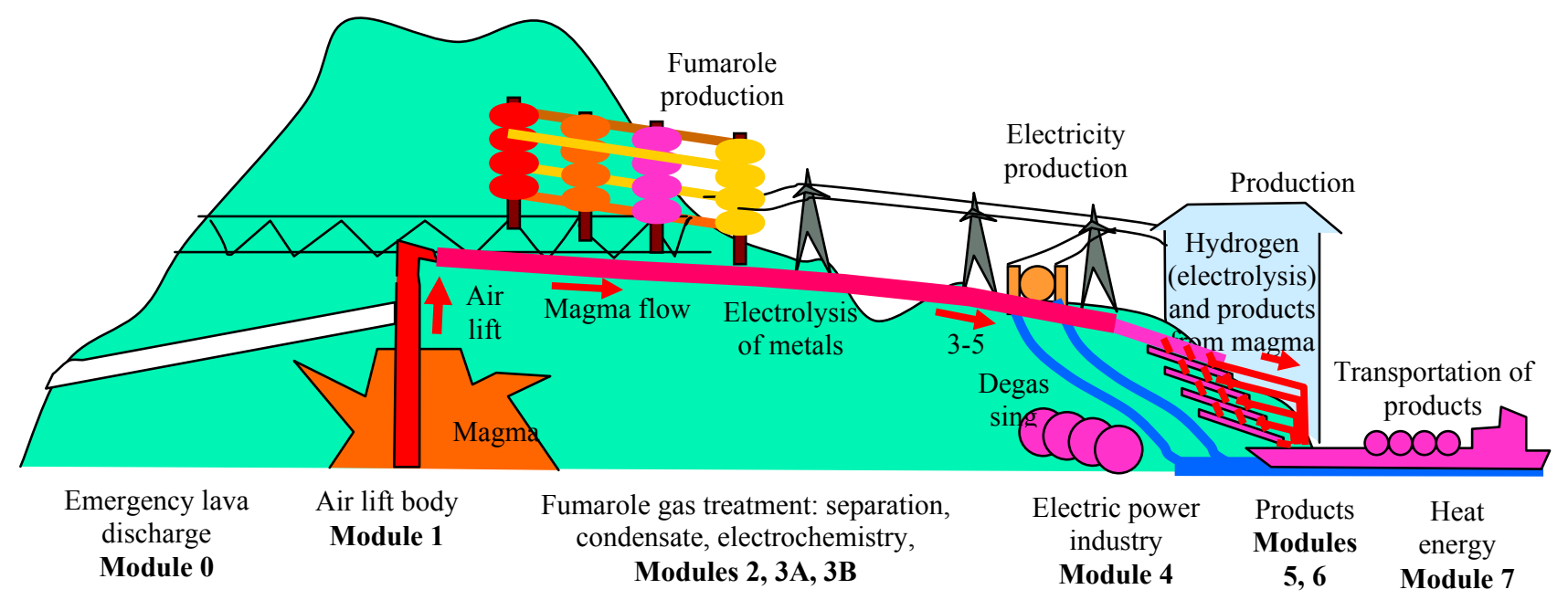

Fig. 7 Macro-circuit of an industrial complex. Scheme of simultaneous functioning of a few parallel production modules.

been studied sufficiently yet. Moreover, these characteristics vary significantly from one volcano to another and also depend on the phase of their activity. More precise data can be obtained in the lab when the specific source of magma is known [7]. The most important fact is that, based on general natural-science considerations, with due account for the specific characteristics of the volcano, it is possible to achieve lava rise, for instance, to a height $\mathrm{H}_{2}$ of 20-60 meters, with the cross section of the riser pipe of up to 2-4 meters and velocity $\mathrm{V}_{1}$ of 0.5 meter per second. It is quite possible to provide the required capacity of the disperser, which is not challenging from the point of view of technology.

This means that:

- The more powerful the disperser, the greater volume of magma in the pipe will be aerated and the higher the amount of magma that can be raised.

- The larger the pipe diameter, the lower the impact on magma from the stationary walls of the pipe and disperser, which increase the viscosity of the magma.

- The deeper the pipe is submerged, the more aerated the magma is and the higher it can be raised.

- Water can be added to the gas supplied into the disperser, which provides for a substantial reduction of the cost of operation.

- If the magma is boiling at a high level, the pipe can be installed at the side of the slope by drilling inclined wells to the magma. This will significantly reduce the turbulence effect.

- The process of enrichment of rare metals from fumarolic gases can be started and managed as early as at the stage of production and formation of fumarole gases.

- The physico-chemical properties of magma can be modified in the process of its raising, and the process of its cooling and solidification can be managed.

\section{Discussion}

The current level of science and technology has allowed discovery of a completely new direction for energy development, associated with lifting volcanic magma and its subsequent use as a high-temperature source for electricity and hydrogen production. Furthermore, partly cooled magma can be recycled as raw material for household needs, such as rare metals, fertilizers, thermal energy, building materials, etc.

The article outlines the airlift method for lifting magma from a volcanic lava lake, which is then directed by gravity flow to a processing line for collection of fumarole gases and integrated processing of magma material. In addition, an example of lifting construction above a volcano crater for installation of a refractory airlift pipe is also examined in the article. 
All the issues arising in this project meet the natural solutions:

- The refractory (titanium) pipe constructions for airlift withstand temperatures many times higher than the temperature of magma.

- The inner voids in the slopes of a volcano are easily identified by geophysical methods and avoided by building constructions.

- The toxicity of volcanic gases is not dangerous for remote and automated control of processed magma flow.

- Velocity of magma lifting increases to the center of a pipe, which provides high flux power in case of large pipe diameter.

- If the magma mirror is not stable, for example, in case of periodic explosions on the surface which do not allow erection of a plant for magma lifting, the structure can be erected on the slope of the volcano by boring a slanted well and entering the magma filled cavity from the side, which would remove the question about the instability of a lava lake.

- Excess electricity produced on a remote island can be used for water electrolysis, and liquefied hydrogen and oxygen can be sold to remote consumers.

- It is worth noting that all problems of the project arising during discussion have always found and find simple technological solutions.

- In case of unexpected induced increase of magma volume in volcano there is an emergency magma drain equipped on the opposite side of the magma pipeline (Fig. 7).

- Magma 22 pipeline heating system is provided in order to keep its temperature stable (in the formation of bubbles, Fig. 2).

- The well for magma lifting can be inclined and penetrate volcano from the side. This can greatly simplify fixing of the entire structure.

General theoretical discussion of airlift plant operation leads to the following conclusions:

It is in accordance with general knowledge about volcanoes and magma. Nonetheless, the above proposal on controlling magma flow has certain requirements of volcanoes, which limits the scope of the plant application. These volcanoes with an open magma mirror or mirror located up to 200 meters lower than sea level. At the same time, new possibilities are arising for conducting deep-laid volcano research by launching "torpedo probes" to depths of $100 \mathrm{~km}$ and more for exploration on processes of the stimulation of volcano eruptions and controlled lifting of magma to the surface.

\section{Conclusions}

To conclude, the proposed method and the device can solve the problem of arranging the controlled raising of lava and sending it for further complex processing, which would launch a new direction in constructive materials engineering, and fumarolic gases can be used to produce rare earth metals.

In essence, this technology lays the foundation for a new source of energy and raw materials industry, which has a potential higher than that of coal, mining, oil and gas industries combined. Other advantages include environmental safety of the method and thorough use of raw materials and energy.

\section{References}

[1] Aprodov, V. 1982. Volcanoes. Moscow: Publishing house Mysl', p. 367.

[2] Balkhanov, V., Bashkuev, Y., and Zhatnuev, N. 2001. "Model of Magma Flow during the Big Crack. Tolbachinsky Eruption (Kamchatka)." Journal of Technical Physics 81 (9): 147-9.

[3] Yushin, N., Vakatov, N., and Pikus, A. 1985. Airlift for molten salt. Patent SU 1182203 A, Russia.

[4] Papayani, F., Pashenko, V., and Koziryatski, L. 1995. Airlifts Encyclopedia. Moscow: InformSvyazIzdat, p. 59.

[5] Chernov, A. A. 2003. "A Model of Magma Solidification during an Explosive Volcanic Eruption." Journal of Applied Mechanics and Theoretical Physics 44 (5): 667-75.

[6] Radionov, A. 2007. "Mathematical Modeling of the Filling of Cracks with Magma." Vladikavkaz Mathematical Journal 9 (4): 26-31.

[7] Titov, V., and Fedotov, S. 1981. Mathematical Modeling of Raising Viscous Magma along a Vertical Dike. Moscow: IAE, p. 24. 